\title{
Individual Patient Data Meta-analysis of Survival and Psychosomatic Self-regulation from Published Prospective Controlled Cohort Studies for Long-term Therapy of Breast Cancer Patients with a Mistletoe Preparation (Iscador)
}

\author{
R. Ziegler ${ }^{1}$ and Ronald Grossarth-Maticek ${ }^{2}$
}

${ }^{1}$ Verein für Krebsforschung, Institut Hiscia, Arlesheim, Switzerland and ${ }^{2}$ Institute of Preventive Medicine, European Centre for Peace and Development (ECPD), Heidelberg, Germany

\begin{abstract}
Mistletoe preparations such as Iscador are in common use as complementary/anthroposophic medications for many cancer indications, particularly for solid cancers. The efficacy is still discussed controversially. This paper presents an individual patient data meta-analysis of all published prospective matched-pair studies with breast cancer patients concerned with longterm application of a complementary/anthroposophic therapy with the mistletoe preparation Iscador. Six sets of data were available for individual patient meta-analysis of breast cancer patients, matched according to prognostic factors into pairs with and without mistletoe (Iscador) therapy. The main outcome measures were overall survival and psychosomatic selfregulation. Overall survival was almost significant in favor of the Iscador group in the combined data set of the randomized studies: estimate of the hazard ratio with $95 \%$ confidence interval $0.59(0.34,1.02)$. Overall survival was highly significant in the combined data set of the non-randomized studies: $0.43(0.34,0.56)$. In the combined analysis of the randomized studies, improvement of psychosomatic self-regulation, as a measure of autonomous coping with the disease, was highly significant in favor of the Iscador group: estimate of the median difference $0.45(0.15,0.80), P=0.0051$. The analyzed studies show that therapy with Iscador might prolong overall survival and improve psychosomatic self-regulation of breast cancer patients.
\end{abstract}

Keywords: breast cancer - Iscador - meta-analysis - mistletoe - quality of life - survival

\section{Background}

In Europe, many women with breast cancer take complementary therapies, however, evidence of its efficacy on disease progression and survival is still a topic of controversial discussion (1). Among the complementary therapies used by breast cancer patients, the aqueous extracts of European mistletoe (Viscum album L.), developed on the basis of anthroposophic medicine, are the most frequently used medications, particularly in German speaking countries $(2,3)$.

For reprints and all correspondence: R. Ziegler, Verein für

Krebsforschung, Kirschweg 9, CH-4144 Arlesheim, Switzerland.

Tel: +41 6170672 45; Fax: +416170672 00; E-mail: ziegler@hiscia.ch
The following report describes an individual patient data meta-analysis $(4,5)$ of all available data concerning breast cancer therapy with the mistletoe preparation Iscador and with the outcomes survival and psychosomatic self-regulation: two randomized and four non-randomized matched-pair studies (6-9). In such an analysis, not the statistical summaries and estimates from the original publications are used, but the raw data from the original studies are pooled and evaluated together.

The three special design features of the studies analyzed below were the matched pairs, the long-term follow-up and the parallel implementation of prospective cohort studies and randomized trials. In addition to the specific outcomes, these features make them different from all other prospective controlled studies $(10,11)$ concerning Iscador

(C) 2008 The Author(s).

This is an Open Access article distributed under the terms of the Creative Commons Attribution Non-Commercial License (http://creativecommons.org/ licenses/by-nc/2.0/uk/) which permits unrestricted non-commercial use, distribution, and reproduction in any medium, provided the original work is properly cited. 
therapy for breast cancer (12-22). Under these circumstances, the results of both randomized and non-randomized matched-pair studies can be compared and hence come with a more reliable internal validity due to randomization (given comparable results), which is enriched by the more reliable generalizability of the nonrandomized cohorts (23).

\section{Patients and Methods}

For more details concerning the background, initial data assessment, the quality of life measurement with psychosomatic self-regulation, the observed therapy and intervention, the patients, the matching process for both randomized and non-randomized studies, the method of exclusion of pairs and the follow-up until 1998, we refer to the original papers (6-8) and the re-analysis (9) of the breast cancer data sets (6).

\section{Psychosomatic Self-regulation}

Quality of life was assessed in these studies as the degree of psychosomatic 'self-regulation'. This term applies to intrinsic activities of a human being through which he or she achieves well-being, inner equilibrium, appropriate stimulation, a feeling of competence and a sense of being able to control stressful situations (6,24-28). Self-regulation is assessed by a self-administered questionnaire and measured on a scale from 1 (low) to 6 (high). Selfregulation influences the incidence and course of cancer. Studies covering a 27-year period and involving 35814 participants (29) showed a higher incidence of cancer in those with poor self-regulation, revealing detrimental synergies between low self-regulation and other cancer risk factors $(29,30)$. In patients with manifest cancer, higher self-regulation correlated with longer survival $(29,30)$.

\section{Objectives}

The main objective of this individual patient data metaanalysis was the evaluation of the overall survival of longterm therapy with Iscador in addition to conventional oncological treatment in patients with primary breast cancer of different stages, compared with standard treatment alone. Survival is measured from the year of first diagnosis until death for any reason (except certified nontumor-related accidents and suicides). In both randomized studies, psychosomatic self-regulation as a measure of autonomous coping with the disease was assessed twice; hence it can be analyzed, whether a therapy with Iscador, in addition to conventional oncological treatment, improves psychosomatic self-regulation in patients with breast cancer in comparison with standard treatment alone.

\section{Designs of Evaluated Studies}

All studies to be evaluated here were controlled cohorts and were prospective by design, that is, all breast cancer patients that were included in this research were recruited beginning in 1971, assessed, matched according to pre-specified relevant prognostic factors and followed up during their life time. The final follow-up happened during 1998.

The matching criteria included: tumor stage at first diagnosis for one of the four diagnostic groups ('first diagnosis'), status of menopause at first diagnosis, year of first diagnosis of the breast cancer stage with up to \pm 3 years difference (data not shown), age at first diagnosis with up to \pm 3 years difference and type of conventional therapy. For details of the matching procedure, the randomization technique and the exclusion of pairs please refer to the original papers $(6,8)$.

In the randomized studies, the data pool for building matched-pairs consisted of breast cancer patients that had never received mistletoe therapy. After randomization it was suggested to one partner of each pair to ask their attending physician (who had no part in the recruitment, selection and matching process) to prescribe them complementary Iscador therapy. If this suggestion was taken up, the pair was included.

In the case of non-randomized studies, if a matching partner could be found within the data base according to the above criteria for each Iscador patient of one of the stage groups, the pair was included.

Patients were followed-up by a team of scientific researchers working for the Institute of Preventive Medicine (Heidelberg). Up to 1998, they made periodically from 1 to several months standardized telephone interviews or home visits performing structured interviews using in each case predetermined case report forms. In the final follow-up during 1998 any dates and causes of death not yet registered were determined from the local resident's registration offices ('Einwohnermeldeamt') and from the local boards of health ('Gesundheitsamt').

\section{Data Sets}

The combined data set MAMMARAND $(2 \times 55$ patients $)$ for the meta-analysis concerns the final raw data from the following randomized matched-pair studies (Table 1): MammaRand: $(2 \times 38$ patients): primary breast cancer patients with no recurrences of the primary tumor, no lymphatic and no distant metastases (8); MammaLym Rand $(2 \times 17$ patients): primary breast cancer patients with only lymphatic metastases and no recurrences $(6,9)$.

The combined data set MAMMA $(2 \times 264$ patients $)$ for the meta-analysis concerns the final raw data from the following non-randomized matched-pair studies (Table 1): Mamma $(2 \times 84$ patients): primary breast cancer with no recurrences of the primary tumor, no lymphatic and no distant metastases (8); MammaRec $(2 \times 42$ patients): primary 
Table 1. Studies of patients with breast cancer and Iscador therapy in matched-pair design

\begin{tabular}{|c|c|c|c|c|c|c|c|c|c|}
\hline \multirow[t]{2}{*}{ Design } & \multirow[t]{2}{*}{ Study } & \multirow[t]{2}{*}{ Indication } & \multicolumn{6}{|c|}{ Pairs of patients } & \multirow[t]{2}{*}{ Published } \\
\hline & & & Recruited & $\begin{array}{l}\text { Therapy } \\
\text { declined } \\
\text { or not } \\
\text { received }\end{array}$ & $\begin{array}{l}\text { Drop-out } \\
\text { after start } \\
\text { of therapy }\end{array}$ & $\begin{array}{l}\text { Lost to } \\
\text { follow-up }\end{array}$ & $\begin{array}{l}\text { Matching } \\
\text { criteria not } \\
\text { fulfilled }\end{array}$ & Final & \\
\hline \multirow[t]{2}{*}{$\begin{array}{l}\text { Randomized } \\
\text { matched-pairs }\end{array}$} & MammaRand & $\begin{array}{l}\text { Breast cancer without } \\
\text { recurrences or metastases }\end{array}$ & 59 & 19 & 0 & 2 & 5 & 38 & (8) \\
\hline & MammaLymRand & $\begin{array}{l}\text { Breast cancer with } \\
\text { lymphatic metastases }\end{array}$ & 17 & 0 & 0 & 0 & 0 & 17 & $(6,9)$ \\
\hline \multirow[t]{3}{*}{$\begin{array}{l}\text { Non-randomized } \\
\text { matched-pairs }\end{array}$} & Mamma & $\begin{array}{l}\text { Breast cancer without } \\
\text { recurrences or metastases }\end{array}$ & 105 & 2 & 0 & 6 & 13 & 84 & (8) \\
\hline & MammaRec & $\begin{array}{l}\text { Breast cancer with only } \\
\text { local recurrences }\end{array}$ & 50 & 5 & 0 & 2 & 1 & 42 & $(6,9)$ \\
\hline & MammaLym & $\begin{array}{l}\text { Breast cancer with } \\
\text { lymphatic metastases }\end{array}$ & 64 & 7 & 0 & 1 & 1 & 55 & $(6,9)$ \\
\hline
\end{tabular}

breast cancer patients with only local recurrences of the primary tumor and no lymphatic or distant metastases (6); MammaLym $(2 \times 55$ patients $)$ : primary breast cancer patients with only lymphatic metastases (6); MammaMet $(2 \times 83$ patients): primary breast cancer patients with distant metastases (6).

\section{Subsets of Original Data Sets}

A patient group of pairs with 'strict matching' is a subgroup of all matched-pairs of patients fulfilling exactly all matching criteria. A patient group with a 'balanced set' is a subgroup of all matched-pairs of patients, where pairs with prognostic factors favoring patients with Iscador therapy were eliminated; they lie in between the complete data set and the set with strict matching. In the individual patient data meta-analysis, these different data sets were combined into sets of pairs with 'strict matching' and 'balanced sets', respectively (see Table 4).

\section{Statistics}

In the first stage of the meta-analysis of overall survival, the means and medians of the times estimated according to Kaplan-Meier were calculated. In addition, the logrank statistic was used, including stratification according to the matched-pairs (31). All $P$-values are two-sided.

In order to explore the sensitivity of the matching criteria in the combined non-randomized studies, the complete data set was compared with the balanced set and the strictly matched set.

In the second stage of the meta-analysis of overall survival, the Cox proportional hazard $(\mathrm{PH})$ regression model was applied to the combined complete data sets from the non-randomized matched-pairs studies. Stratification according to matched-pairs was applied, that is, we performed a conditional analysis accounting for matching. This generally produces a conservative estimate compared with the unmatched analysis (32) (§ 7.1). In addition, a stratification according to the individual data sets (see above) was applied. The model development and the assessment of model adequacy were performed according to recommendations (33,34). An automatic variable selection procedure was not used. An adjustment of prognostic factors in the combined analysis of the randomized studies was not performed. According to the recommendations (34) the assumption of $\mathrm{PH}$ was checked statistically and graphically; if any one, but not both, of these methods fails to show a positive result, we say that the PH assumption is 'moderately fulfilled'.

Confidence intervals (CI) are always 95\% CI and test results were judged as significant, if $P<0.05$. The statistical analyses were performed using S-Plus 7.0 for Windows Professional Edition (Insightful Corp. 2005, Seattle, WA, USA). The Wilcoxon paired sample (WPS) tests, the Hodges-Lehmann estimates (35) and the marginal homogeneity tests were calculated for $n<100$ using the exact procedures from StatXact 7 (Cytel Software Corporation 2005, Cambridge, MA, USA).

\section{Results}

\section{Patient Characteristics for Combined Randomized Matched-pair Studies (Table 2)}

\section{MAMMARAND $(n=2 \times 55$, Table 2)}

The matching was perfect for the variables stage (FIGO, TNM) and grading. Concerning therapies, there were some minor differences in operation, chemotherapy and radiotherapy and larger differences in the case of hormone therapy. Most differences, particularly in the case of 
Table 2. Distribution of patient characteristics of the combined study MAMMARAND

\begin{tabular}{|c|c|c|c|c|c|}
\hline \multirow{2}{*}{$\begin{array}{l}\text { Prognostic } \\
\text { variables }\end{array}$} & & & \multicolumn{2}{|c|}{$M A M M A R A N D$} & \multirow{2}{*}{$\begin{array}{l}\text { WPS } \\
P\end{array}$} \\
\hline & & & $\begin{array}{l}\text { Iscador } \\
n=55\end{array}$ & $\begin{array}{l}\text { Control } \\
n=55\end{array}$ & \\
\hline \multirow{26}{*}{$\begin{array}{l}\text { Matching } \\
\text { variables }\end{array}$} & FIGO & TNM & & & \\
\hline & I & T1aN0M0 & 23 & 23 & \\
\hline & IIA & T2N0M0 & 7 & 7 & \\
\hline & IIB & T3N0M0 & 8 & 8 & \\
\hline & IIIA & $\mathrm{T} 2 \mathrm{~N} 2 \mathrm{M} 0$ & 1 & 1 & \\
\hline & & T3N1-2M0 & 5 & 5 & \\
\hline & IIIB & $\mathrm{T} 4 \mathrm{~N} 1-4 \mathrm{M} 0$ & 10 & 10 & \\
\hline & & T3N3M0 & 1 & 1 & \\
\hline & Grading & & & & \\
\hline & 1 & & 26 & 26 & \\
\hline & 2 & & 3 & 3 & \\
\hline & 3 & & 4 & 4 & \\
\hline & NA & & 22 & 22 & \\
\hline & Menopause & & & & \\
\hline & Prae & & 12 & 12 & \\
\hline & post & & 5 & 5 & \\
\hline & NA & & 38 & 38 & \\
\hline & Age at first diagnosi & & & & \\
\hline & Mean & & 50.22 & 50.31 & \\
\hline & $\mathrm{SD}$ & & 7.56 & 7.69 & \\
\hline & Range & & $33-63$ & $34-62$ & \\
\hline & Conventional therapy & & & & \\
\hline & Operation & & 55 & 54 & \\
\hline & Chemotherapy & & 24 & 25 & \\
\hline & Radiotherapy & & 25 & 27 & \\
\hline & Hormone therapy & & 9 & 16 & \\
\hline \multirow{4}{*}{$\begin{array}{l}\text { Baseline } \\
\text { variable }\end{array}$} & Self-regulation & & & & 0.51 \\
\hline & Mean/median & & $3.63 / 3.70$ & $3.54 / 3.60$ & \\
\hline & $\mathrm{SD}$ & & 0.80 & 0.76 & \\
\hline & Range & & $1.7-5.5$ & $1.7-5.5$ & \\
\hline \multirow{4}{*}{$\begin{array}{l}\text { Therapy } \\
\text { variable }\end{array}$} & Iscador use (years) & & & & \\
\hline & Mean/median & & $8.47 / 7.00$ & NA & \\
\hline & SD & & 5.84 & & \\
\hline & Range & & $0.08-20.83$ & & \\
\hline
\end{tabular}

Abbreviations: WPS, Wilcoxon paired sample test; SD, standard deviation; NA, not available.

hormone therapy, chemotherapy and radiotherapy, work in favor of the control group, i.e. patients of the control group had on average more of these therapies than those of the Iscador group. However, since these were randomized matched-pairs, there is no reason to believe that this leads to a systematic bias. Self-regulation at baseline was not matched; the difference between the therapy groups was not significant (WPS-test, $P=0.51$ ).
Table 3. Distribution of patient characteristics of the combined study $M A M M A$

\begin{tabular}{|c|c|c|c|c|c|}
\hline \multirow{2}{*}{$\begin{array}{l}\text { Prognostic } \\
\text { variables }\end{array}$} & & & \multicolumn{2}{|c|}{$M A M M A$} & \multirow{2}{*}{$\begin{array}{l}\text { Test } \\
P\end{array}$} \\
\hline & & & $\begin{array}{l}\text { Iscador } \\
n=264\end{array}$ & $\begin{array}{l}\text { Control } \\
n=264 \\
\end{array}$ & \\
\hline \multirow{24}{*}{$\begin{array}{l}\text { Matching } \\
\text { variables }\end{array}$} & FIGO & TNM & & & $0.99^{\mathrm{b}}$ \\
\hline & I & T1N0M0 & 53 & 53 & \\
\hline & IIA & T2N0M0 & 25 & 26 & \\
\hline & IIB & T3N0M0 & 32 & 31 & \\
\hline & & T2N1M0 & 3 & 3 & \\
\hline & III & T4N0M0 & 16 & 16 & \\
\hline & IIIA & $\mathrm{T} 2 \mathrm{~N} 2 \mathrm{M} 0$ & 5 & 5 & \\
\hline & & T3N2M0 & 5 & 5 & \\
\hline & IIIB & $\mathrm{T} 1-3 \mathrm{~N} 3 \mathrm{M} 0$ & 6 & 6 & \\
\hline & & T4N1-4M0 & 36 & 36 & \\
\hline & IV & TXNXM1 & 83 & 83 & \\
\hline & Menopause & & & & $0.99^{\mathrm{a}}$ \\
\hline & Prae & & 28 & 26 & \\
\hline & Post & & 121 & 123 & \\
\hline & NA & & 115 & 115 & \\
\hline & Age at first diagnosis & & & & $0.97^{\mathrm{c}}$ \\
\hline & Mean & & 54.86 & 54.84 & \\
\hline & SD & & 8.40 & 8.51 & \\
\hline & Range & & $32-70$ & $29-70$ & \\
\hline & Conventional therapy & & & & \\
\hline & Operation & & 264 & 264 & $0.99^{\mathrm{a}}$ \\
\hline & Chemotherapy & & 133 & 118 & $<0.01^{\mathrm{a}}$ \\
\hline & Radiotherapy & & 133 & 135 & $0.82^{\mathrm{a}}$ \\
\hline & Hormone therapy & & 92 & 90 & $0.79^{\mathrm{a}}$ \\
\hline \multirow{4}{*}{$\begin{array}{l}\text { Baseline } \\
\text { variable }\end{array}$} & Self-regulation & & & & $<0.01^{\mathrm{c}}$ \\
\hline & Mean/median & & $3.87 / 4.00$ & $3.47 / 3.55$ & \\
\hline & SD & & 1.19 & 1.01 & \\
\hline & Range & & $1.0-6.0$ & $1.0-6.0$ & \\
\hline \multirow{4}{*}{$\begin{array}{l}\text { Therapy } \\
\text { variable }\end{array}$} & Iscador use (years) & & & NA & \\
\hline & Mean/median & & $4.62 / 3.00$ & & \\
\hline & SD & & 4.66 & & \\
\hline & Range & & $0.08-23.83$ & & \\
\hline
\end{tabular}

Abbreviations: SD, standard deviation; NA, not available: ${ }^{\mathrm{a}} \mathrm{MN}$, McNemar test; ${ }^{b} \mathrm{MH}$, Marginal homogeneity test; ${ }^{\mathrm{c}} \mathrm{WPS}$, Wilcoxon paired sample test.

\section{Patient Characteristics for Combined Non-randomized Matched-pair Studies (Table 3)}

Three sets were analyzed and compared in the sensitivity analysis: (i) combined complete data sets, (ii) combined balanced data sets: exclusion of pairs, the risk factors of which were in favor of the mistletoe patient, (iii) combined reduced data sets consisting of all pairs with strict matching 
Table 4. Descriptive statistics of survival

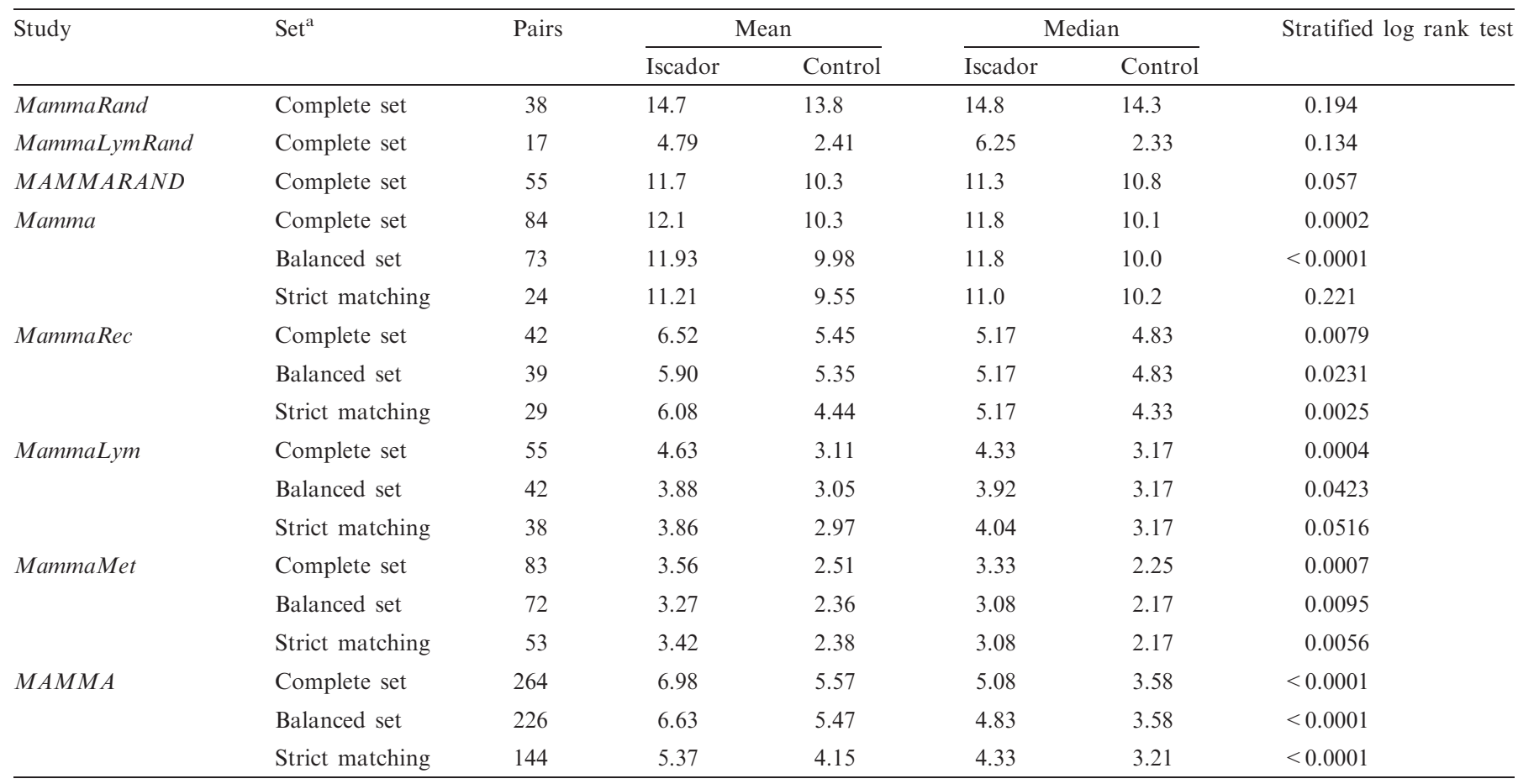

${ }^{a}$ Groups with a 'balanced set' form subgroups of complete sets of matched-pairs not favoring the patients with Iscador therapy; groups with 'strict matching' form subgroups of complete sets of matched-pairs of patients fulfilling exactly all matching criteria.

allowing no deviations. Details concerning the deviations from the strict matching within the groups (i) and (ii) can be found in the literature $(8,9)$.

\section{MAMMA (Table 3)}

For the complete set $(n=2 \times 264)$, the difference in the stages and in the status of menopause between the two groups was not significant (MH-test, $P=0.99$ ). Concerning therapies, differences in chemotherapy were judged as relevant, which was also significant (MN-test, $P=0.007)$ in favor of the Iscador group. For radiotherapy, the situation was judged as balanced (MN-test, $P=0.82$ ). Concerning age at first diagnosis, the difference was not significant (WPS-test, $P=0.97$ ).

On this basis, 38 pairs had to be eliminated since the Iscador patients seemed to be favored by the distribution of the prognostic factors, in particular chemotherapy, in the end producing a balanced set of 226 pairs. Strict matching, i.e. with no exceptions in all matching variables, produced 144 pairs. Psychosomatic self-regulation at baseline was not matched; the difference between the therapy groups in the first evaluation of self-regulation was significant (WPS-test, $P=0.0005$ ).

\section{Overall Survival}

Overall survival was analyzed for all data sets in four ways (see Tables 3 and 4): (i) descriptive analysis; (ii) stratified log-rank test on the basis of the matched-pairs; (iii) randomized matched-pairs studies: $\mathrm{Cox} \mathrm{PH}$ model with no adjustment for other variables than Iscador therapy; (iv) non-randomized matched-pairs studies: $\mathrm{Cox} \mathrm{PH}$ model fitted to all available prognostic factors with subsequent retrospective elimination and assessment of model adequacy.

The data set MAMMARAND that combines the data sets MammaRand and MammaLymRand, was analyzed in full descriptively (stratified log-rank test, $P=0.057$ ) and with a Cox PH models: estimate of the hazard ratio with 95\% CI: 0.59 (0.34, 1.02), PH assumption moderately fulfilled (Table 4, Fig. 1). In the individual randomized studies, MammaRand (censored values in 16 patients) and MammaLymRand (no censored values), however, the effects were not significantly in favor of the Iscador therapy (Tables 4, 5). Since there were no censored survival times in MammaLymRand, and the PH assumption was definitely not fulfilled for this data set, we calculated an estimate of the median of the pair wise differences of the survival times Iscador versus control: 2.5 (0.83, 4.50), $P=0.018$, with the Hodges-Lehmann procedure, which produced a significant result.

In a similar fashion, the data set $M A M M A$, which combines the data sets Mamma, MammaRec, MammaLym and MammaMet, was analyzed descriptively and with a Cox $\mathrm{PH}$ model. It turned out that the $\mathrm{PH}$ assumption in the adjusted model was moderately fulfilled; this model 

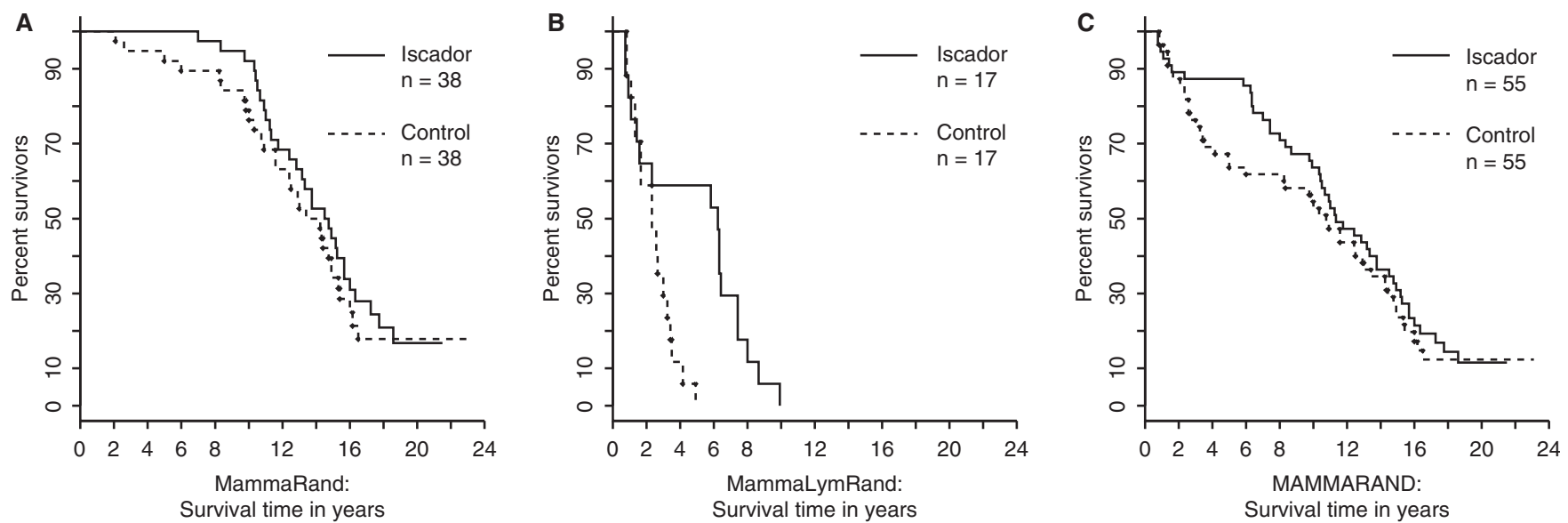

Figure 1. (A) MammaRand; (B) MammaLymRand and (C) MAMMARAND: Kaplan-Meier survival curves for the complete sets.

Table 5. Individual patient data meta-analysis with final Cox models for survival for the combined data sets MAMMARAND and MAMMA

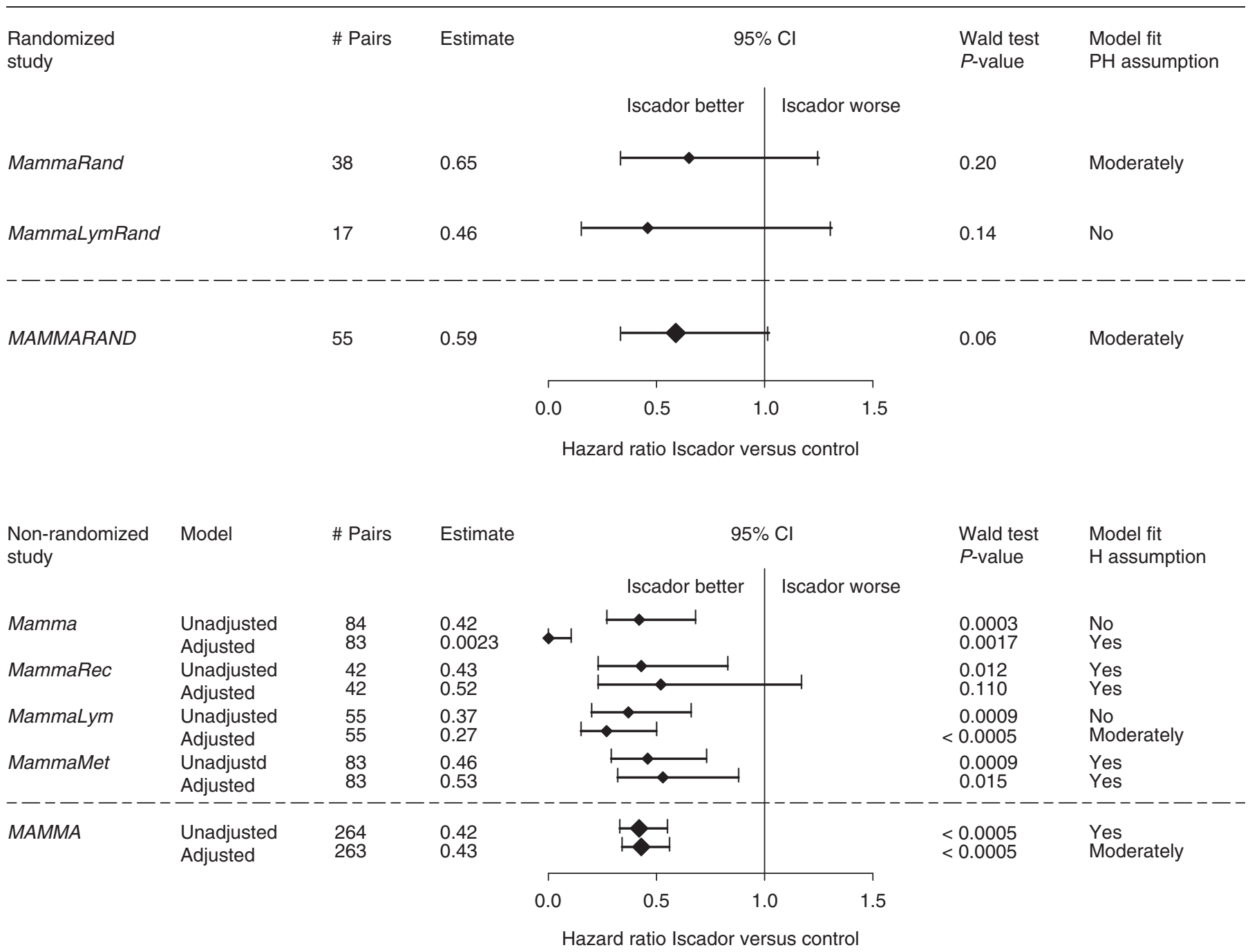

The hazard ratio estimate measures the Iscador versus the control group and the $P$-value from the Wald test measures the significance of the estimated variable Iscador treatment ( $\mathrm{PH}$, proportional hazards, see Statistics section). In MAMMA there is 1 pair with a missing value in the variable self-regulation, and there are no significant interactions; the only significant adjustment factor is self-regulation $(P<0.001)$ measured at initial data assessment. 


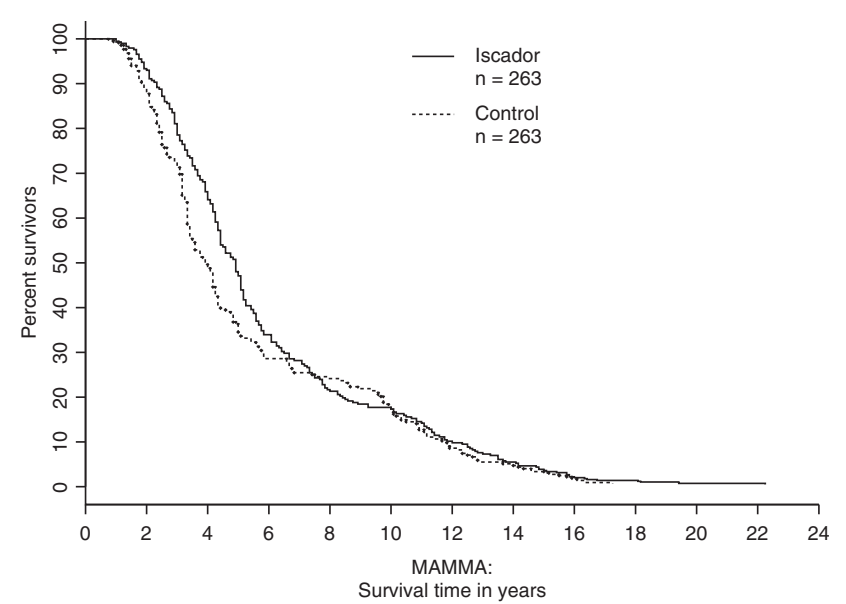

Figure 2. Adjusted survival curves for $M A M M A$ based on the model from Table 5 (MAMMA has 264 matched-pairs with 1 pair having a missing value in the variable self-regulation. The adjusted variable is complete self-regulation; there are no significant interactions; the $\mathrm{PH}$ assumption is moderately fulfilled).

produces a highly significant result: $0.43(0.34,0.56)$, $P<0.0005$ (Table 5, Fig. 2). The stratified log-rank test gives $P<0.0001$ in all three cases (complete set, balanced set, strict matching, Table 4). In Fig. 2, the majority of all patients $(73.5 \%)$ have survival times below 8 years; hence the first third of the figure is the most relevant part. The results of the individual non-randomized studies Mamma, MammaRec, MammaLym and MammaMet mirror these effects and show at least positive trends in favor of the Iscador group and in most cases highly significant results.

\section{Self-regulation}

Psychosomatic self-regulation was only assessed twice for the data sets MammaRand, MammaLymRand and Mamma. The second assessment for Mamma and Mamma Rand took place 12 months after initial data assessment (in the form of a structured personal interview with standardized checklists) and for MammaLymRand 3 months after initial data assessment. For the two randomized sets of matched-pairs MammaRand and Mamma LymRand, the complete sets of both sets individually and combined were analyzed by the WPS-test together with the Hodges-Lehmann procedure estimating the median of the pair wise differences of the second versus the first evaluation of self-regulation: $0.35 \quad\left(\begin{array}{lll}0.05, & 0.60)\end{array}\right.$ $(P=0.034), 0.90(0.00,1.75)(P=0.055)$, combined 0.45 $(0.15,0.80)(P=0.0051)$. For Mamma, the WPS-test was applied to the complete set, the balanced set and the set with strict matching: $0.20(0.00,0.35)(P=0.031), 0.15$ $(0.00,0.35)(P=0.055)$ and $0.30(0.05,0.60)(P=0.014)$, respectively. Hence nearly all studies show significant improvements or at least strong trends: Iscador therapy might have had helped to improve psychosomatic selfregulation of breast cancer patients, as a measure of autonomous coping with the disease.

\section{Discussion}

\section{Design and Analysis}

An integrative approach was chosen to evaluate the complex interplay of factors that may influence the prognosis of cancer in real life, i.e. a combination of nonrandomized controlled epidemiological studies with randomized intervention trials within the same cohort. Using this approach, the results of randomized trials with high internal validity (reliability results) can be integrated into the results of non-randomized studies with, in general, high external validity (generalizability). For this reason, we attempted to add a randomized intervention trial for the same indication and from the same cohort of patients for every cancer indication investigated by a nonrandomized controlled epidemiological study. However, due to financial and logistical constraints, this was only possible in the stage groups of breast cancer without lymphatic and distant metastasis and breast cancer with only lymphatic metastases.

The reason for applying different types of analysis is to demonstrate the strength or the sensitivity of the results against different sets of constraints. Particularly, nonrandomized studies are susceptible to different types of biases (36) that can be dealt with, to a certain extent, by comparing the results of different statistical approaches.

\section{Randomized Matched-pairs}

Overall, the results of the data set MAMMARAND, which combines the randomized matched-pairs studies Mamma Rand (breast cancer without recurrences and without metastases, 38 pairs) and MammaLymRand (breast cancer with only lymphatic metastases, 17 pairs), show at least strong positive trends in favor of the long-term complementary Iscador therapy versus conventional treatment alone.

Concerning overall survival, the individual patient data meta-analysis for all randomized matched-pairs was almost significant in favor of the Iscador group in the descriptive analysis (log rank test, $P=0.057)$ as well as in the Cox model [estimate for hazard ratio: $0.59(0.34,1.02)]$.

Concerning the short-term improvement of psychosomatic self-regulation, the combined data set MAMMA $R A N D$ shows significant improvements: estimate of the median difference $0.45(0.15,0.80)$. In MammaLymRand the estimate of the median of improvement was 0.9 on a scale from 1 to 6 . As there was no significant difference in the baseline values in MAMMARAND (Table 2), also minor improvements with respect to the Iscador group might be of some clinical relevance (25).

\section{Non-randomized Matched-pairs}

Overall, the results of the data set MAMMA that combines the non-randomized studies Mamma, MammaRec, 
MammaLym, MammaMet, show highly significant results in favor of the Iscador group in all cases.

Particularly, when concerning overall survival, all results of the unadjusted evaluations were significantly in favor of the Iscador group (Table 4). This compares well with the corresponding adjusted $\mathrm{Cox} \mathrm{PH}$ model of MAMMA with the following estimate for hazard ratio: $0.43(0.34,0.56)$ (Table 5$)$. In this case, self-regulation was a significant $(P<0.001)$ predictor of the outcome and included in the model, therefore.

For the different subsets, the unadjusted analyses show comparable results (Table 4), proving that the original sets were fairly well balanced across the different therapy groups, at least with respect to the prognostic factors used in the matching process. This is supported by the fact that the results of the Cox PH model in most individual studies do not differ very much between adjusted and unadjusted analyses [Table 5, details in $(8,9)]$. Also, in the combined set MAMMA, the results of the unadjusted analysis for the hazard ratio was $0.42(0.33,0.55)$, which is very close to the above mentioned value.

\section{Consistency and Generalizability}

The baseline values and the results of the randomized matched-pair trial MammaRand and the non-randomized matched-pair study Mamma were well comparable (8) (Tables 3 and 4). That is, although not significant in all cases, the results of the randomized trial MammaRand were consistent with the results of Mamma: they point in the same direction. Together, both studies gain from each other: the first has the stronger validity and the latter the stronger generalizability.

For MammaLymRand and MammaLym, the situation is more complex. The patients from the latter were $\sim 15$ years older at the time of first diagnosis and have a much higher level of self-regulation (9) (Tables 3 and 4). Still, the results for survival in MammaLymRand as well as for MammaLym were convincing in favor of Iscador therapy. The results of the combined data sets MAMMARAND and $M A M M A$ also point in the same direction and could be interpreted as complementing each other.

For survival of breast cancer patients of all stages, particularly without metastases, there is evidence from other controlled studies in favor of mistletoe therapy, particularly Iscador $(12,37)$. In addition, research based on archival data show a significant advantage for Iscador therapy on survival $(38,39)$.

Concerning the short term effects of Iscador therapy on psychosomatic self-regulation of breast cancer patients, the results of the randomized trials Mamma Rand, MammaLymRand and their combined data set MAMMARAND, as well as those of the non-randomized study Mamma, were highly consistent. They compare well with other randomized trials on the effect of mistletoe therapy on the overall quality of life of breast cancer patients $(13,40,41)$. In addition, two recently published non-randomized controlled studies with Iscador therapy in addition to conventional therapy versus conventional therapy alone show similar effects $(15,16)$.

\section{Causality}

The question certainly arises, whether the reported associations in the non-randomized matched-pairs studies between survival and therapy with the mistletoe preparation Iscador were effects of unknown origin or causally related to this therapy. The foregoing considerations show that these effects were not spurious: they were significant in nearly all cases. Although bias and confounding cannot be ruled out in non-randomized studies, the consistent results of the randomized trials and the non-randomized parallel studies suggest a residual effect that is due to the therapy with Iscador alone.

The main conditions of the causal character of an association include (42-45): (i) strong association, (ii) temporal sequence, (iii) consistency of results with results of studies with different design and different populations, (iv) doseresponse relationship, (v) biological plausibility of clinical effects.

Condition (i) was fulfilled in most studies reported above and condition (ii) in all of them. According to the considerations in the previous section, condition (iii) was also fulfilled. There was no explicit evidence for (iv) and, up until now, no explicitly empirically validated theory for (v). Hence, there is some evidence for a causal relationship between the therapy with Iscador and effects on survival; at least, there is absolutely no evidence against the hypothesis of such a causal relationship.

\section{Tolerability and Safety}

The documentation of unintended adverse drug reactions of a therapy with Iscador has not been part of the design of these studies. However, there is no evidence for severe adverse effects that can plausibly be related to this therapy [see the overviews $(3,46,47)]$. This has also been supported by newer data on the tolerability and safety of a complementary therapy with Iscador in the treatment of breast cancer (39). In addition, apart from its effects on the prolongation of survival and the delay of tumor progression, mistletoe therapies reduce the side effects of conventional chemotherapy of gynecological cancers $(15,16,39,41)$ that is, this type of complementary therapy helps patients to achieve a better quality of life, despite the impairments of chemotherapy.

\section{Conclusions}

The consistency of results across randomized and nonrandomized studies, as well as across different types of analyses, gives some evidence that a long-term therapy 
with mistletoe preparations, particularly Iscador, has a clinically relevant prolonging effect on survival. In the short term, psychosomatic self-regulation, as a measure of autonomous coping with the disease, increases significantly more under Iscador therapy than under conventional therapy alone. Overall, therapy with Iscador seems to prolong survival and to improve psychosomatic selfregulation of breast cancer patients.

\section{Acknowledgements}

The analysis of the data and the preparation of this article were financed by the Society for Cancer Research, Arlesheim.

\section{References}

1. Cassileth BR, Deng G. Complementary and alternative therapies for cancer. Oncologist 2004;9:80-9.

2. Moschen R, Kemmler G, Schweigkofler H, Holzner B, Dünser M, Richter R, et al. Use of alternative/complementary therapy in breast cancer patients - a psychological perspective. Support Care Cancer 2001;9:267-74.

3. Kienle GS, Kiene H. Die Mistel in der Onkologie: Fakten und konzeptionelle Grundlagen. Stuttgart: Schattauer, 2004.

4. Clarke MJ, Stewart LA. Obtaining individual patient data from randomised controlled trials. In: Egger M, Davey Smith G, Altman DG (eds). Systematic Reviews in Health Care: MetaAnalysis in Context. London: BMJ, 2001, 109-21.

5. Stewart LA, Clarke MJ. Practical methodology of meta-analysis (overviews) using updated individual patient data. Stat Med 1995; 14:2057-79.

6. Grossarth-Maticek R, Kiene H, Baumgartner S, Ziegler R. Use of Iscador, an extract of European mistletoe (viscum album), in cancer treatment: prospective nonrandomized and randomized matchedpairs studies nested within a cohort study. Altern Ther Health Med 2001;7:57-78

7. Grossarth-Maticek R, Kiene H, Baumgartner S, Ziegler R. Addendum to Iscador article. Altern Ther Health Med 2001;7:26.

8. Grossarth-Maticek R, Ziegler R. Prospective controlled cohort studies on long-term therapy of breast cancer patients with a mistletoe preparation (Iscador). Forsch Komplementarmed 2006; 13:285-92.

9. Grossarth-Maticek R, Ziegler R. Randomised and non-randomised prospective controlled cohort studies in matched pair design for the long-term therapy of breast cancer patients with a mistletoe preparation (Iscador): a re-analysis. Eur J Med Res 2006;11:485-95.

10. Kienle GS, Kiene H. Complementary cancer therapy: a systematic review of prospective clinical trials on anthroposophic mistletoe extracts. Eur J Med Res 2007;12:1-17.

11. Ziegler R. Mistletoe preparation Iscador: are there methodological concerns with respect to controlled clinical trials? eCAM 2007, doi: $10.1093 /$ ecam $/$ nem 121 .

12. Salzer G. 30 Jahre Erfahrung mit der Misteltherapie an öffentlichen Krankenanstalten. In: Leroi R (ed). Misteltherapie Eine Antwort auf die Herausforderung Krebs. Stuttgart: Verlag Freies Geistesleben, 1987, 173-215.

13. Borrelli E. Valutazione della qualità di vita in pazienti affette da adenocarcinoma mammario sottoposte a terapia con viscum album. Med Biol 1999(Luglio-Settembre):27-30.

14. Von Hagens C, Loewe-Mesch A, Kuehn JJ, Abel U, Gerhard I. Prospektive kontrollierte nicht randomisierte Machbarkeits-Studie $\mathrm{zu}$ einer postoperativen simultanen Mistel-/Chemotherapie bei Patientinnen mit Mammakarzinom - Ergebnisse zu Rekrutierund Randomisierbarkeit, Immunparametern, Lebensqualität und Verträglichkeit. In: Scheer R, Bauer R, Becker H, Fintelmann V, Kemper FH, Schilcher H (eds). Fortschritte in der Misteltherapie: Aktueller Stand der Forschung und klinische Anwendung. Essen: KVC Verlag, 2005, 567-78.
15. Toelg M, Antonu H, Reiss B, Ramos MH. Lebensqualität von Tumorpatientinnen unter begleitender Misteltherapie - Ergebnisse einer prospektiven, nicht randomisierten, kontrollierten, offenen Studie (AWB) mit Iscador M. Schweiz Z Ganzheitsmed 2005; 17:294-9.

16. Toelg M, Reiss B, Antonu H. Chemotherapie mit begleitender Misteltherapie - Prospektive, nicht randomisierte, kontrollierte, offene Studie (AWB) zur Lebensqualität. CO'MED 2005;11:18-22.

17. Carlsson M, Arman M, Backman M, Hamrin E. Perceived quality of life and coping for Swedish women with breast cancer who choose complementary medicine. Cancer Nurs 2001;24:395-401.

18. Carlsson M, Arman M, Backman M, Flatters U, Hatschek T, Hamrin E. Evaluation of quality of life/life satisfaction in women with breast cancer in complementary and conventional care. Acta Oncol 2004;43:27-34.

19. Carlsson M, Arman M, Backman M, Hamrin E. Coping in women with breast cancer in complementary and conventional care over 5 years measured by the mental adjustment to cancer scale. $J$ Altern Complement Med 2005;11:441-7.

20. Carlsson M, Arman M, Backman M, Flatters U, Hatschek T, Hamrin E. A five-year follow-up of quality of life in women with breast cancer in anthroposophic and conventional care. eCAM 2006;3:523-31.

21. Büssing A, Bischof M, Hatzmann W, Bartsch F, Soto Vera D0, Fronk E-M, et al. Prevention of surgery-induced suppression of granulocyte function by intravenous application of a fermented extract from Viscum album L. in breast cancer patients. Anticancer Res 2005;25:4753-8.

22. Büssing A. Immune modulation using mistletoe (Viscum album L.) extracts Iscador. Arzneimittelforschung/Drug Res 2006;56:508-15.

23. Walach H, Falkenberg T, Fønnebø V, Lewith G, Jonas WB. Circular instead of hierarchical: methodological principles for the evaluation of complex interventions. BMC Med Res Methodol 2006, doi: 10.1186/1471-2288-6-29.

24. Grossarth-Maticek R, Schmidt P, Vetter H, Arndt S. Psychotherapy research in oncology. In: Steptoe A, Matthews A (eds). Health Care and Human Behavior. New York: Academic Press, 1984, 325-41.

25. Grossarth-Maticek R, Eysenck H-J. Self-regulation and mortality from cancer, coronary heart disease, and other causes: a prospective study. Pers Individ Dif 1995;19:781-95.

26. Grossarth-Maticek R. Selbstregulation, Autonomie und Gesundheit. Krankheitsfaktoren und soziale Gesundheitsresourcen im sozio-psychobiologischen System. Berlin: Walter de Gruyter, 2003.

27. Grossarth-Maticek R, Eysenck H-J, Boyle GJ, Heeb J, Costa SD, Diel IJ. Interaction of psychosocial and physical risk factors in the causation of mammary cancer, and its prevention through psychological methods of treatment. J Clin Psychol 2000;56:33-50.

28. Grossarth-Maticek R. Autonomietraining, Gesundheit und Problemlösung durch Anregung der Selbstregulation. Berlin: Walter de Gruyter, 2000.

29. Grossarth-Maticek R. Systemische Epidemiologie und präventive Verhaltensmedizin chronischer Erkrankungen. Strategien zur Aufrechterhaltung der Gesundheit. Berlin: Walter de Gruyter, 1999.

30. Stierlin H, Grossarth-Maticek R. Krebsrisiken - Überlebenschancen. Wie Körper, Seele und soziale Umwelt zusammenwirken. Heidelberg: Carl-Auer-Systeme, 1998.

31. Klein JP, Moeschberger ML. Survival Analysis: Techniques for Censored and Truncated Data. New York: Springer, 1997.

32. Hougaard P. Analysis of Multivariate Survival Data. New York: Springer, 2000.

33. Hosmer DW, Lemeshow S. Applied Survival Analysis: Regression Modeling of Time to Event Data. New York: Wiley, 1999.

34. Tableman M, Kim JS, Portnoy S. Survival Analysis Using S: Analysis of Time-to-Event Data. Boca Raton: Chapman \& Hall/ CRC, 2004.

35. Lehmann EL. Non-parametrics: Statistical Methods Based on Ranks. San Francisco: Holden-Day, 1975.

36. Reeves BC. Reasons for caution when evaluating health care interventions using non-randomised study designs. Forsch Komplementarmed 2004;11(Suppl 1):40-5.

37. Gutsch J, Berger H, Scholz G, Denck H. Prospektive Studie beim radikal operierten Mammakarzinom mit Polychemotherapie, Helixor und unbehandelter Kontrolle. Deutsche Zeitschrift für Onkologie 1988;20:94-101. 
38. Hellan J, Salzer G, Wutzlhofer F. Das operierte Mammakarzinom retrospektive Auswertung. In: Jungi WF, Senn HJ (eds). Krebs und Alternativmedizin, Band II. Berlin: Springer, 1990, 63-69.

39. Bock PR, Friedel WE, Hanisch J, Karasmann M, Schneider B. Wirksamkeit und Sicherheit der komplementären Langzeit behandlung mit einem standardisierten Extrakt aus Europäischer Mistel (Viscum album L.) zusätzlich zur konventionellen adjuvanten onkologischen Therapie bei primärem, nicht metastasiertem Mammakarzinom. Ergebnisse einer multizentrischen, komparativen, retrolektiven, epidemiologischen Kohortenstudie in Deutschland und der Schweiz. Arzneim/Drug Res 2004;54:456-66.

40. Heiny BM. Additive Therapie mit standardisiertem Mistelextrakt reduziert die Leukopenie und verbessert die Lebensqualität von Patientinnen mit fortgeschrittenem Mammakarzinom unter palliativer Chemotherapie (VEC-Schema). Krebsmed 1991;12:3-14

41. Piao BK, Wang YX, Xie GR, Mansmann U, Matthes H, Beuth J, et al. Impact of complementary mistletoe extract treatment on quality of life in breast, ovarian and non-small cell lung cancer patients. A prospective randomized controlled clinical trial Anticancer Res 2004;24:303-10.
42. Doll R. Proof of causality: deduction from epidemiological observation. Perspect Biol Med 2002;45:499-515.

43. Grimes DA, Schultz KF. Bias and causal associations in observational research. Lancet 2002;359:248-52.

44. Susser M. What is a cause and how do we know one? A grammar for pragmatic epidemiology. Am J Epidemiol 1991;133:635-48.

45. Ziegler R. Elements of therapeutic research structure. Forsch Komplementarmed 2004;11(Suppl 1):5-12.

46. Stein GM, Berg PA. Adverse effects during therapy with mistletoe extracts. In: Büssing A (ed). Mistletoe - The Genus Viscum. Amsterdam: Harwood Academic Publishers, 2000, 195-208.

47. Saller R, Kramer S, Iten F, Melzer J. Unerwünschte Wirkungen der Misteltherapie bei Tumorpatienten - Eine systematische Übersicht. In: Scheer R, Bauer R, Becker H, Fintelmann V, Kemper FH, Schilcher H (eds). Fortschritte in der Misteltherapie: Aktueller Stand der Forschung und klinische Anwendung. Essen: KVC Verlag, 2005, $367-403$.

Received January 10, 2007; accepted March 13, 2008 


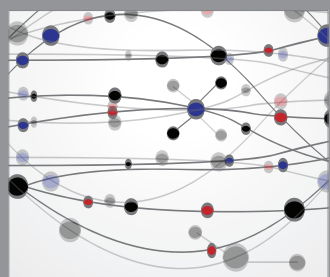

The Scientific World Journal
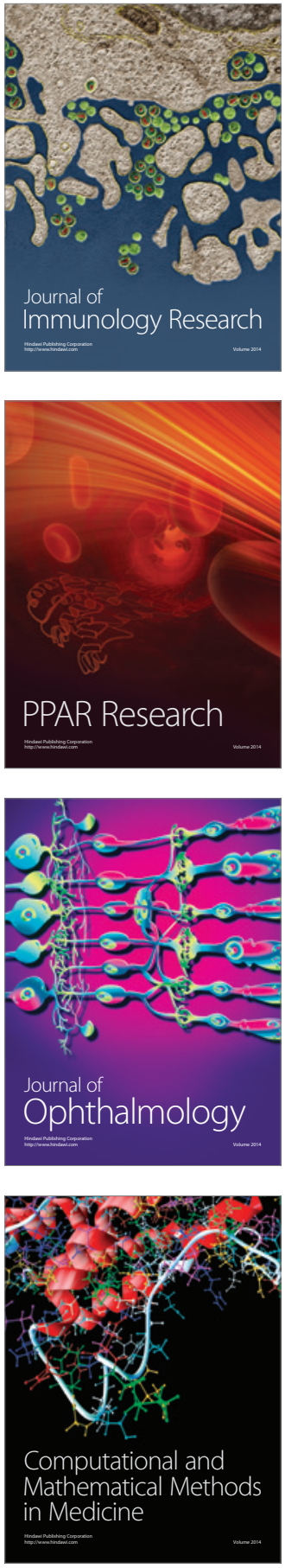

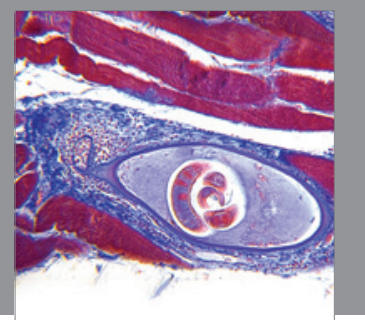

Gastroenterology

Research and Practice
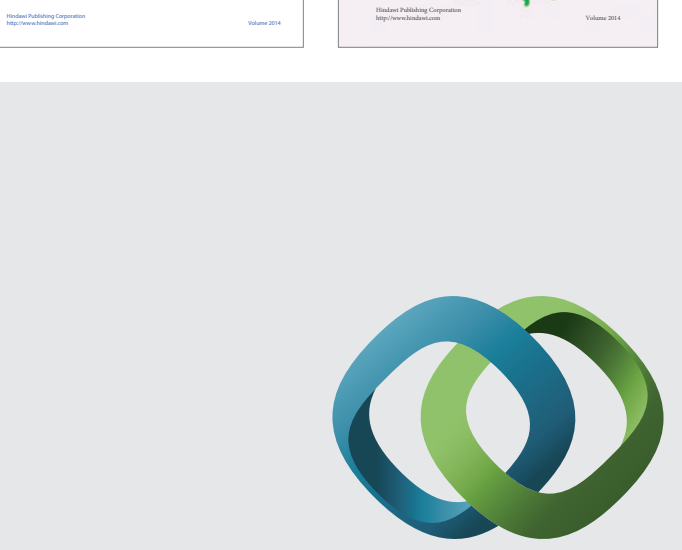

\section{Hindawi}

Submit your manuscripts at

http://www.hindawi.com
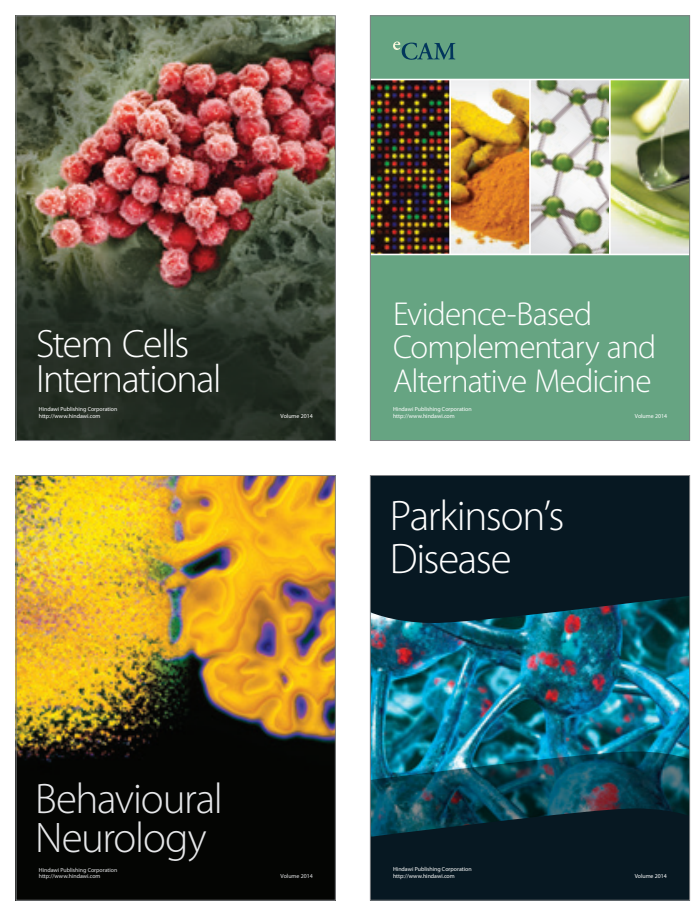

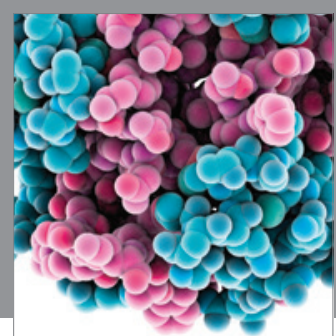

Journal of
Diabetes Research

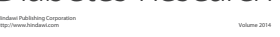

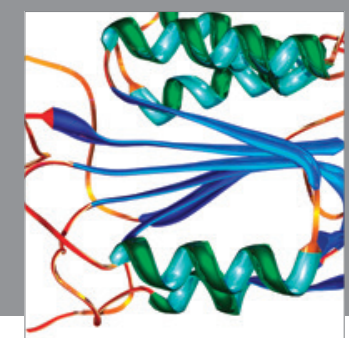

Disease Markers
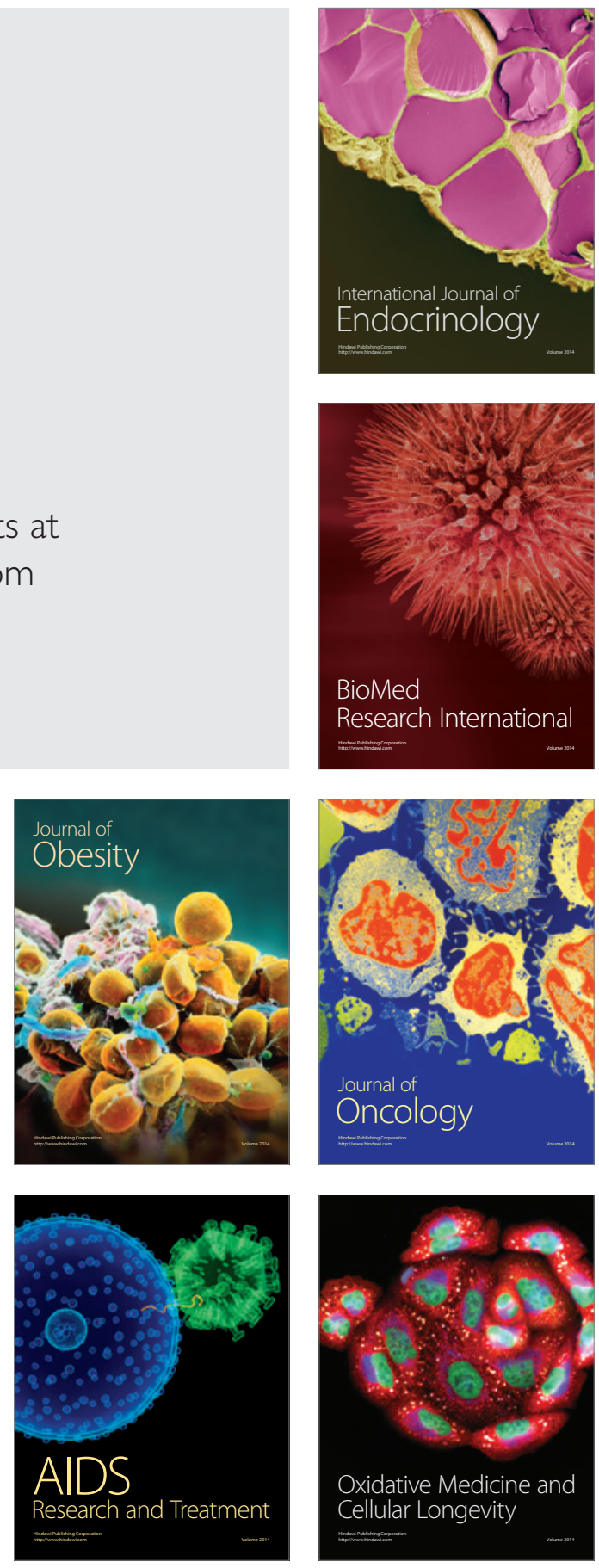